\title{
La cuestión del otro: forasteros, extranjeros, extraños y monstruos
}

\author{
Amaia Izaola \\ Imanol Zubero \\ Universidad del País Vasco / Euskal Herriko Unibertsitatea. Grupo de investigación \\ CIVERSITY \\ amaia.izaola@ehu.es \\ imanol.zubero@ehu.es
}

\section{Resumen}

La sociología y la antropología han teorizado la cuestión de la otredad recurriendo a cuatro conceptos o tipos ideales (el forastero, el extranjero, el extraño y el monstruo), cada uno de los cuales constituye una aproximación particular al fenómeno de la diferencia. Cada uno de ellos transmite una imagen muy distinta del sujeto o del colectivo al que se define como "otro»: una imagen de relativa proximidad en unos casos, una imagen de alejamiento y hasta de diferencia radical en otros. A partir de estos cuatro constructos teóricos, proponemos la elaboración de un mapa conceptual que define espacios de cercanía o de distancia social en función de la mayor o menor diferencia atribuida al sujeto o a los sujetos definidos como «otro".

Palabras clave: diversidad; inmigración; distancia social; teoría sociológica; otredad.

Abstract. Otherness: Outsiders, foreigners, strangers and monsters

Sociologists and anthropologists have theorized the idea of otherness through four archetypal figures - the outsider, the foreigner, the stranger, and the monster - each of which constitutes a particular approach to the phenomenon of difference. Each of these figures conveys a very different image of the person or group branded as 'other', with some figures suggesting a degree of closeness and similarity, whilst others imply great or even radical difference. Using these four theoretical constructs, the authors propose a conceptual map that defines spaces of social distance depending on the degree of difference a particular society attributes to a subject or subjects defined as 'other'.

Keywords: diversity; immigration; social distance; sociological theory; otherness. 


\author{
Sumario \\ El encuentro con el Otro y la Extraños \\ construcción de la distancia social \\ Forasteros \\ Extranjeros \\ Monstruos \\ Conclusión \\ Referencias bibliográficas
}

El Otro ha ocultado al otro.

(Bartra, 2008: 38)

\title{
El encuentro con el Otro y la construcción de la distancia social
}

Como señala Kapuści'nski, «el encuentro con el Otro, con personas diferentes, ha constituido la experiencia básica y universal de nuestra especie», experiencia que hemos resuelto recurriendo a una de estas tres estrategias: la guerra, el aislamiento o el diálogo (2007: 11-12, 14-15). La pregunta que subyace a este trabajo puede plantearse así: ¿cómo y por qué el Otro se convierte en un Otrodialogable, un Otro-aislable o un Otro-guerreable? Partimos de la idea de que la definición que hacemos del Otro condiciona nuestra relación con él. Es sobre todo a través del discurso y de la imaginación como se construye la diferencia etnocultural (Collier, 2001; Ono y Sloop, 2002; Santamaría, 2002b; Lakoff y Ferguson, 2007; Cohen, 2011), pues «también los discursos son acontecimientos, motores de la historia, y no solamente sus representaciones» (Todorov, 2010: 15). Compartimos la perspectiva que Benhabib denomina «constructivismo social» y que la autora utiliza como herramienta teórica para combatir los intentos de «reificar» o cosificar las diferencias culturales (2006: 28-33). Esta perspectiva no afirma que las diferencias etnoculturales sean puramente ficticias o irreales, sino que dependen fundamentalmente de las propias definiciones de la realidad: como las comunidades nacionales, las diferencias etnoculturales son imaginadas, pero no «imaginarias» (Anderson, 2006: 24).

Todos los grupos humanos construyen imágenes de los considerados Otros como una forma de autoidentificación (Choza, 2008: 78). Sea como sea, debemos ser conscientes de que estas imágenes son eso, imágenes, construcciones sociales elaboradas mediante la selección arbitraria de ciertos rasgos diferenciales de esas personas o grupos. Es el caso del orientalismo, la imagen que Occidente se ha hecho de Oriente a lo largo de la historia: «una visión política de la realidad cuya estructura acentuaba la diferencia entre lo familiar (Europa, Occidente, "nosotros") y lo extraño (Oriente, el Este, "ellos")» (Said, 2003: 73). Cuando se considera que las categorías de oriental y occidental se refieren a realidades prácticamente "naturales», la consecuencia es, "por un lado, la polarización de la distinción: el oriental se vuelve más oriental y el occidental, más occidental y, por otro, la limitación de las relaciones humanas entre las diferentes culturas, tradiciones, y sociedades» (2003: 76). Se trata de una cues- 
tión de poder, de una relación de dominación (Delphy, 2008; Sayad, 2010: 173-198). Sabemos, desde que fuera formulado como principio por William I. Thomas en los años 30, que si una situación es definida como real, es real en sus consecuencias; pero sabemos también que solo llegan a tener consecuencias aquellas definiciones respaldadas por alguna forma de poder (político, económico, simbólico, militar). El orientalismo es una perspectiva al servicio de la dominación, tanto un juicio de valor como un programa de acción: «Desde el momento en que el oriental era miembro de una raza sometida, tenía que ser sometido; era así de simple» (Said, 2003: 278-279).

En este artículo, profundizamos en la manera como las ciencias sociales han teorizado la otredad, atendiendo a cuatro poderosas imágenes o tipos ideales: el forastero, el extranjero, el extraño y el monstruo. Consideramos que estas conceptualizaciones permitirían construir una cartografía de la otredad, un mapa conceptual que defina espacios potenciales de cercanía y distancia social entre la población autóctona y los distintos colectivos de inmigrantes. Consideramos que, si bien desde una perspectiva filosófica, puede ser cierto que «reconocer la radical alteridad "del Otro" no significa que no haya manera de entender al otro» y que, en este sentido, «incluso una relación asimétrica es una relación» (Bernstein, 1991: 21), desde una perspectiva sociológica cabe pensar en representaciones discursivas del otro cuya radical alteridad haga imposible cualquier forma de relación caracterizada por la existencia de un sentido recíproco que oriente la acción mutua. Retomamos, en este sentido, la reflexión clásica de Park $(1924,1926,1999)$ sobre las relaciones humanas en términos de posición y de distancia social, con su énfasis en la importancia de la definición de la situación, en la significación subjetiva de la diferencia y en su representación, cuya capacidad de estructurar la acción social ha sido testada en el ámbito educativo (Terrén, 2001). Porque lo cierto es que, como advierte el geógrafo francés Georges Benko, "hay Otros que son más Otro que Otros» (citado en Bauman, 2002: 117).

\section{Forasteros}

El forastero, el otro más próximo en el espacio de la otredad, es, según Schütz (2003: 95): «una persona adulta, perteneciente a nuestra época y civilización, que trata de ser definitivamente aceptada, o al menos tolerada, por el grupo al que se aproxima», e identifica algunos ejemplos que aclaran a quiénes se está refiriendo: «El postulante a socio de un club exclusivo, el pretendiente que desea ser aceptado por la familia de su novia, el hijo del campesino que ingresa en la universidad, el habitante de la ciudad que se establece en un medio rural, el "recluta" que se incorpora al ejército, la familia del obrero de una industria bélica que se traslada a una población económicamente próspera» ${ }^{1}$. Todos

1. Como es sabido, Schütz publica su ensayo sobre el forastero en American Journal of Sociology en 1944, con el título: «The Stranger: An Essay in Social Psychology». El diccionario Oxford traduce el término stranger como "desconocido» o «forastero». Tanto el Wodsworth como 
ellos se disponen "a ingresar en un grupo que no es ni ha sido nunca el suyo» (Schütz, 2003: 108) ${ }^{2}$, pero la caracterización del forastero se aclara definitivamente cuando señala quiénes no forman parte de esta categoría: «Excluimos intencionalmente de nuestro examen ciertos casos cuya inclusión exigiría condicionar en alguna medida nuestros enunciados: $a$ ) el visitante o el huésped que intenta establecer un contacto meramente transitorio con el grupo; $b$ ) los niños o los primitivos, $\mathrm{y} c$ ) las relaciones entre individuos y grupos de diferentes niveles de civilización, como en el caso de los indios hurones llevados a Europa» (Schütz, 2003: 95).

¿Cuál es el problema que plantea ese forastero con quien, en todo caso, se comparte "civilización»? Aunque la realidad de la que procede no sea muy diferente de aquella en la que quiere asentarse, cuando el forastero se hace presente, pasa a ser alguien que cuestiona gran parte de lo que parece incuestionable para los miembros del grupo al que se aproxima, con lo cual rompe la normalidad de quienes viven su vida cotidiana con total naturalidad. Recién llegado a una sociedad que no es la suya, el forastero experimenta la pauta cultural dominante no como un "refugio protector» - experiencia propia de los sujetos que ya forman parte de esa realidad-, sino como «un laberinto en el cual ha perdido todo sentido de orientación» (Schütz, 2003: 107). Esta experiencia de desorientación explica que el forastero se haga preguntas, cuestione la realidad a la que accede y, con ello, los fundamentos de la concepción natural del mundo de los miembros del endogrupo (Schütz, 2003: 106). No es que juzgue negativamente o rechace esa realidad, simplemente la interroga para aclararse, procurando entenderla. Porque, como señala Schütz citando a Park y Stonequist, el forastero se encuentra en la situación del hombre marginal, «un híbrido cultural que vacila entre dos pautas diferentes de vida grupal sin saber a cuál de ellas pertenece» (2003: 106).

Esta situación, en la que la simple aparición del forastero problematiza la realidad considerada normal o evidente, nos recuerda a la figura del nómada,

el Collins añaden a estos dos la idea de «extraño». Como ocurrirá también con el trabajo de Simmel, la primera dificultad a la que nos enfrentamos cuando queremos utilizar sus trabajos es de naturaleza terminológica. En este artículo, optamos por utilizar el término forastero, no sólo porque coincide con la traducción castellana de la obra de Schütz, sino también por considerar que el contenido que el autor le confiere se corresponde con la definición más usual que del término forastero ofrece el Diccionario de la Real Academia: 1. "Que es o viene de fuera del lugar». 2. "Dicho de una persona: Que vive o está en un lugar de donde no es vecina y donde no ha nacido». Sin ignorar, por supuesto, que encontramos una tercera definición que vuelve a situarnos en el terreno de la discusión terminológica: 3 . «Extraño, ajeno».

2. El planteamiento de Schütz coincide, en lo fundamental, con la distinción de Elias entre establecidos y forasteros (2003: 213-215). En ambos casos, el forastero es un recién llegado a un grupo que no es el suyo y donde busca ser admitido o tolerado. Sin embargo, frente a la perspectiva integracionista o de «ajuste social» de Schütz, Elias analiza una realidad en la que las relaciones entre establecidos y forasteros se plantean en términos de «miedo a la contaminación», lo que las asemeja más a situaciones relacionadas con las categorías de extraño o de monstruo que abordaremos más adelante. En esto, Elias se aparta también de la mirada positiva hacia la interacción social entre desconocidos de Simmel (Alcalde, 2011: 379). 
del hombre errante, portador de novedades y, por ello, objeto de desconfianza por parte de los establecidos, cuya trascendencia en la sociología de la Escuela de Chicago es destacada por Maffesoli (2004: 41, 44): «En un país en que el tema de la frontera desempeñó un papel importante en la constitución del imaginario colectivo, los sociólogos de la Escuela de Chicago subrayaron la importancia del hombre errante, del vagabundo en la ciudad moderna. El "caminante", como su nombre lo indica, cumple de algún modo con el papel de mala conciencia", sacude el orden establecido y viene a encarnar, debido a su movilidad y a su extraterritorialidad, «el rompimiento, el desbordamiento, en pocas palabras, lo imprevisible». Con mayor o menor intensidad en función de su posición en el espacio de la distancia social, esta capacidad de perturbación de la normalidad con la que los establecidos viven su existencia cotidiana es la característica más destacada de todo «otro-entre-nosotros», convertido sin pretenderlo en alter ego del establecido, del autóctono, del nacional, con lo cual revela «sus insuficiencias personales a la vez que de los vicios de las costumbres y las instituciones» (Kristeva, 1991: 162).

Como hemos dicho más arriba, en su situación marginal, el forastero se ve obligado a realizar una constante reinterpretación de las pautas culturales de las que se sirve para manejarse en el nuevo entorno social, experimentado como «un campo de aventura» (Schütz, 2003: 106). En esta situación de incertidumbre, el forastero únicamente dispone de entrada de su propia pauta o marco cultural para intentar interpretar las reglas y los códigos de la sociedad a la que acaba de llegar. Como señalan Berger y Kellner (1985: 55-67), «la interpretación es también una forma de incorporación: avanzo en la comprensión de lo nuevo relacionándolo con lo viejo en mi propia experiencia», en el caso del forastero, que comparte civilización con el grupo al que busca incorporarse, esta interpretación no es excesivamente complicada, ya que esa cultura compartida le permite tener «esquemas interpretativos preparados "a mano" para habérselas con una realidad social desconocida». Así pues, es perfectamente lógico que el forastero afronte la tarea de leer e interpretar su nuevo ambiente social «en términos de su pensar habitual» (Schütz, 2003: 100). Al fin y al cabo, es ese pensar habitual, esa pauta cultural propia, lo único que el forastero puede utilizar con una cierta seguridad.

El problema es que ese conocimiento propio del forastero, si bien puede servirle como esquema para intentar interpretar al grupo extraño, no sirve como guía para su interacción con éste: se trata de un conocimiento que se refiere a los miembros del nuevo grupo exclusivamente como objetos de interpretación, pero no "como destinarios de posibles actos surgidos del resultado del procedimiento interpretativo, ni como sujetos de reacciones previstas hacía esos actos» (Schütz, 2003: 101). Este conocimiento objetivador sería adecuado en el caso de un analista social, pero el forastero no quiere ser un mero observador no participante, sino que aspira a convertirse en miembro de ese grupo. Este «salto de la platea al escenario» no resulta sencillo y el forastero experimenta una sensación de desubicación que no se resuelve aceptando la nueva pauta cultural sin más, que el forastero no puede dar por sentada, ya 
que no puede evitar preguntarse solamente por su cómo, sino también por su porqué; por ello, «debe contar con que aparecerán discrepancias fundamentales en la visión de las cosas y el manejo de las situaciones», lo cual convertirá el esfuerzo del forastero por incorporarse a la nueva realidad social en «un intento de conquistar las pautas extrañas como esquema de expresión» (Schütz, 2003: 101-105), cuyo éxito no está garantizado:

Para el forastero que se incorpora al grupo, la pauta de éste último no garantiza una probabilidad objetiva de éxito, sino una posibilidad puramente subjetiva que debe ser verificada paso a paso; en otras palabras, debe asegurarse de que las soluciones sugeridas por el nuevo esquema también producirán el efecto deseado para él, en su especial situación de extraño y recién llegado que no ha logrado captar todo el sistema de la pauta cultural, cuya incongruencia, incoherencia y falta de claridad, en cambio, lo desconciertan. (Schütz, 2003: 105)

$\mathrm{Si}$, a pesar de todas las dificultades, el forastero logra ampliar y ajustar su acervo de experiencias de manera que «lo que antes era un hecho extraño y un problema que desconcertaba [su] mente se transforma en un elemento adicional de [su] conocimiento justificado", habrá logrado con éxito su necesario ajuste social, su adaptación a la nueva realidad, con lo cual dejará de ser forastero (Schütz, 2003: 107). En el caso de que este ajuste social no sea completo, es probable que sufra la acusación de «dudosa lealtad» por parte de los miembros del endogrupo. En ocasiones, esta acusación puede no ser un mero prejuicio por parte del grupo abordado. Ello se debe al hecho de que el forastero «no quiere o no puede sustituir totalmente la pauta cultural de su grupo de origen por la nueva pauta cultural», pero este reproche responde, la mayoría de las veces, a la incomprensión de los miembros del endogrupo hacia el hecho mismo de ser forastero y las dificultades que comporta (Schütz, 2003: 106-107). Esta falta de comprensión explica muchas actitudes de rechazo a la inmigración. Vivimos con tanta naturalidad nuestra pauta cultural que nos cuesta ponernos en el lugar de ese «otro» tantas veces perdido y desorientado entre códigos y normas que le resultan extraños. Si esta incomprensión, con los problemas de convivencia y relación social que genera, se produce en el caso del forastero, ya podemos suponer que las dificultades se multiplican a medida que avanzamos en el espacio teórico de la distancia social.

\section{Extranjeros}

Cuando, en la actualidad, hablamos de «extranjeros», no hay excesivas dudas respecto de a quienes nos referimos. Como señala Benhabib (2005: 13): «el sistema moderno de estados nación ha regulado la pertenencia en términos de una categoría principal: la ciudadanía nacional» y, en el marco de este sistema, «las políticas definen a algunos como miembros, a otros como extranjeros». En el lenguaje cotidiano, el término extranjero tiene un significado evidente y unívoco: aquel que, viviendo entre nosotros, tiene la nacionalidad de otro estado. En un mundo como el actual, donde tantas personas habitan como 
extranjeras durante largos periodos de tiempo en países que no son el suyo por razones muy diversas, es habitual recurrir a Simmel y a su «digresión sobre el extranjero» para analizar el fenómeno de la inmigración (Raphael, 1986; Fichet, 1993; Choza, 1994; Rammstedt, 1994; Chaouite, 1997; Germain, 1997; Santamaría, 1994, 2002a; Gallego, 2000; Martínez, 2000; Thériault, 2003; Alexander, 2004; Wagner, 2006; Cachón, 2008; Penchaszadeh, 2009; Rea y Tripier, 2009; Alcalde, 2011). Sin embargo, como señaló hace más de cuatro décadas McLemore (1970), el concepto de extranjero propuesto por Simmel es uno de los «más intrigantes» de la sociología contemporánea. De hecho, en diversas obras, dicho concepto se traduce como forastero (Reséndiz, 1998) o como extraño (Beck, 2000; Béjar, 2005; Cachón, 2008; Aguiluz, 2009; Ribeiro, 2009). Esta variedad de sentidos puede explicarse por la ambigüedad del término utilizado por Simmel, Fremden, rico en matices y con distintos significados en castellano (Waldenfels, 1998: 85-87). En nuestro caso, utilizamos el término extranjero por ser la forma en que se ha traducido al castellano la obra de Simmel, en continuidad con sus primeras traducciones al inglés (Wolff, 1950).

Simmel aborda su "digresión sobre el extranjero» tras analizar fenómenos de movilidad espacial como el nomadismo, la migración o el vagabundaje (1977: 701-716). Compartimos con Rammstedt la necesidad de leerla no como un texto aislado, sino como parte de la reflexión de Simmel sobre el espacio y la sociedad, para no caer en errores de interpretación (Rammstedt, 1994: 148), pues, aunque la figura simmeliana del extranjero resulta de utilidad para analizar el fenómeno contemporáneo de las migraciones internacionales, Simmel no maneja la misma imagen de extranjero que podemos tener en la actualidad. Esta figura es definida así:

El extranjero a quien vamos a referirnos no es el nómada migrador, en el sentido que hemos dado a esta palabra hasta ahora, no es el que viene hoy y se va mañana, es el que viene hoy y se queda mañana; es, por decirlo así, el emigrante en potencia, que, aunque se haya detenido, no se ha asentado completamente. Se ha fijado dentro de un determinado círculo espacial -0 de un círculo cuya delimitación es análoga a la espacial—, pero su posición dentro de él depende esencialmente de que no pertenece a él desde siempre, de que trae al círculo cualidades que no proceden ni pueden proceder del círculo. (Simmel, 1977: 716)

Simmel resume la naturaleza del extranjero en una sugerente fórmula: es un «lejano [que] está próximo» (1977: 716-717). Igual que el forastero, el extranjero comparte determinadas características con la sociedad a la que llega, pero trae consigo "cualidades que no proceden ni pueden proceder» de esa sociedad; hay elementos comunes, pero también diferencias: «El extranjero nos es próximo en cuanto sentimos que entre él y nosotros se dan igualdades sociales, profesionales o simplemente humanas; en cambio, nos es lejano en cuanto que esas igualdades están por encima de ambos, y sólo nos ligan porque ligan asimismo a otros muchos» (Simmel, 1977: 720). 
Como ocurría con el forastero, la simple aparición del extranjero rompe la normalidad, al mantener una actitud de distanciamiento crítico frente a las normas y a las instituciones propias de la sociedad en la que se ha asentado, actitud que Simmel denomina la «objetividad» del extranjero; objetividad que le confiere una importante libertad: «El hombre objetivo no se encuentra ligado por ninguna consideración, que pudiera ser un prejuicio para la percepción, la compresión y la estimación de los objetos» (Simmel, 1977: 718-719). Es como si pudiera observar la realidad «a vista de pájaro», al no encontrarse constreñido por los diferentes intereses del grupo (Santamaría, 1994; Chaouite, 1997). Pero esta libertad y esta objetividad no están exentas de problemas, similares a los que Schütz plantea sobre la «dudosa lealtad» del forastero:

Esta libertad, merced a la cual el extranjero percibe, como a vista de pájaro, la relación de proximidad, contiene, es cierto, diversas posibilidades peligrosas. De antiguo, en algaradas de todo género, el partido atacado sostiene que ha mediado una excitación procedente de afuera, llevada a cabo por enviados o agitadores extranjeros. Cuando tal imputación es cierta, hay en ella siempre una exageración del papel específico del extranjero, que se encuentra libre, práctica y teóricamente, y considera las circunstancias sin prejuicios, las mide a la luz de ideales más generales y objetivos, y no se siente atado en su acción por hábitos, afectos ni precedentes. (Simmel, 1977: 719)

Aunque, en situaciones sociales adversas, la libertad distanciada del extranjero puede hacer que recaigan sobre él la ira y el enfado de la sociedad (Raphael, 1986: 76), Simmel (1977: 717) considera la relación de extranjería como «una relación perfectamente positiva, una forma especial de acción recíproca", que puede, a pesar de los elementos de distanciamiento, llegar a constituir «una forma de colaboración y de recíproca unidad». En esto no se distingue de la perspectiva de Schütz. Pero, a diferencia de éste, Simmel incorpora un elemento inquietante, que denomina "extrañeza», y que puede derivar en la ruptura de toda relación positiva cuando comenzamos a pensar que lo que nos une a otras personas es algo de naturaleza tan general que carece de valor: «Es la extrañeza que surge de sentir que, aunque existe entre dos personas igualdad, armonía, proximidad, estas conjunciones no son patrimonio exclusivo de tal relación, sino algo general que, en potencia, puede darse entre nosotros en incontables personas, mas sin que corresponda con necesidad interior y exclusiva a aquella relación». Más aún, considera que "existe un género de "extranjería", en el cual está excluida la comunidad a base de algo general, común a las dos partes», y pone como ejemplo «la relación del griego con el "bárbaro", y, en general, todos los casos en que se niegan al otro las cualidades que se sienten como propiamente humanas». Llegados a este extremo, nuestra relación con el extranjero se convierte en una no-relación: "Ya no es lo que se supone en todas las consideraciones precedentes: un miembro del grupo» (Simmel, 1977: 721).

Simmel introduce, así, un elemento fundamental para analizar los siguientes dos tipos ideales de otredad: nos referimos a las dinámicas de distanciamiento que nacen no de la existencia de diferencias que podemos considerar 
«objetivas» (lengua, costumbres, rasgos fenotípicos), sino de consideraciones estrictamente subjetivas, que convierten en «otros» incluso a quienes son miembros del propio grupo.

\section{Extraños}

El análisis de esta categoría de otredad nos exige, como advierte Beck (2000: 129), familiarizarnos con la paradoja: «La categoría de extraño es el contraconcepto (o transconcepto) de todos los conceptos del orden social. Y aquí radica su irritación y provocación —ya como concepto» (Beck, 2007: 54). En efecto, si anteriormente hemos analizado categorías construidas sobre la base de elementos objetivos o, cuando menos, objetivables (como la distancia geográfica o cultural), ahora nos movemos por un terreno donde el principio de categorización es esencialmente subjetivo. Compartimos con Clarke (2002: 347) que la idea del extraño desarrollada por Bauman presenta un «carácter psicososocial que es en parte ficticio, en parte real y en parte un producto de nuestra imaginación». Iniciamos la reflexión con una anécdota narrada por Beck. Una mujer afroalemana paseaba por una playa africana cuando unos niños le gritaron: «iRosa!, ¡Rosa!»; la mujer, que pretendía «encontrar su identidad en África», se sintió desconcertada, hasta que encontró una explicación a lo sucedido:

Mi comportamiento, distante, de observadora, me había delatado. En aquel escenario yo me había comportado, por una parte, con un claro distanciamiento $y$, por otra, mostrando un excesivo interés para ser una nativa. Mi conducta me había delatado como europea; y como, según el cliché, los europeos son blancos, enseguida me identificaron con una Rosa. «Rosa», en ese momento, era una categoría social, de la misma manera que sucede entre nosotros con «negra». (Beck, 2000: 133)

Aunque Beck no lo señala expresamente, lo relevante es que la mujer era «realmente» negra. «Esta inversión de papeles —advierte- no solo nos pone de manifiesto lo que significa la relatividad de lo extraño, sino también en qué escasa medida lo extraño y los extraños, al definirse y al identificarse, se conciben y se determinan con bases naturales y biológicas» (Beck, 2000: 133). Esta experiencia indica que cualquiera puede ser considerado un extraño.

Como señala Beck (2000: 133), «hay nativos y extranjeros, amigos y enemigos; $y$, aparte, extraños, que no encajan en esas categorías contrapuestas, que subyacen a ellas, las invaden o las violentan». En el mismo sentido, Bauman (2005a: 84) afirma: «Hay amigos y enemigos. Y también hay extraños». Un extranjero no es necesariamente un extraño, pero puede acabar siéndolo; lo mismo puede ocurrirle a un nativo, incluso a un vecino. Esta posibilidad marca la diferencia entre esta categoría de otredad y las anteriores: "Los extraños son unos vecinos de los que se dice (este es el quid de la cuestión): ¡estos no son como "nosotros"!» (Beck, 2000: 131). Lo relevante es la forma en que puede producirse esta transformación. Beck analiza esta cuestión desde la perspectiva 
de la construcción política del extraño, a saber, el extraño es alguien sometido a un proceso de definición o de conversión en extraño: «La categoría de extraño quiere decir: distanciamiento de los próximos de parte de los cercanos, que no tiene por qué darse de mutuo acuerdo» (Beck, 2000: 131). Los extraños están, siempre, «delimitados por los otros» (Beck, 2007: 55). La experiencia de los judíos alemanes durante el nazismo se convierte para Beck en paradigma de esta conversión, tal y como señala una placa conmemorativa de la deportación y el exterminio de miles de ciudadanos judíos de Hamburgo:

La dificultad para elegir las palabras «Ciudadanos judíos de Hamburgo» señala el problema que quiero tratar: no eran los «judíos» como raza (Rassejuden) (Leyes de Nuremberg), sino los vecinos (judíos), a quienes el odio excitado públicamente y las medidas burocráticas convirtieron en extraños, en judíos de raza y sangre ajena que tenían que ser «extirpados del cuerpo político alemán» (de acuerdo con la formulación nada disimulada de las «Leyes para la protección de la sangre alemana»). (Beck, 2007: 48)

"Cómo, de vecinos, se hacen judíos hoy en día y en el futuro» (Beck, 2000: 127). Esta preocupación justifica la relevancia de la categoría de extraño en cualquier reflexión sobre la inmigración actual. Los extraños pueden manifestarse de múltiples maneras: «Pueden aparecer como el extranjero que viene de otro país o como el transeúnte anónimo de las grandes ciudades, que no conocemos; también pueden adquirir el rostro de aquel que expresa una serie de pautas culturales diferentes, como el forastero o el hombre marginal» (Sabido, 2009: 30-31). Cualquier inmigrante, sea cual sea su procedencia, puede acabar convertido en un extraño, con las consecuencias que ello supone; pero también puede convertirse en un vecino, es decir, en parte de un Nosotros que es cada vez más complejo y plural. Que sea una cosa u otra dependerá, fundamentalmente, de nuestra mirada, de la manera en que sea construida la imagen de las personas inmigrantes que viven entre nosotros y la comunidad que vamos conformando.

La experiencia de los judíos alemanes durante el nazismo es también fundamental para la reflexión de Bauman sobre el extraño. Bauman (2010: 127) analiza el Holocausto como ejemplo de asesinato categorial, entendiendo por ello la eliminación física de hombres, mujeres y niños "por el simple hecho de que habían sido asignados a una categoría de seres que tenía que ser exterminada como tal». Esta eliminación masiva solo fue posible tras un proceso de "producción social de la distancia» (Bauman, 1997: 251), cuyo resultado fue la desaparición de los judíos como sujetos individuales, sustituidos por una categoría abstracta construida mediante prejuicios y estereotipos. La construcción de este judío abstracto hizo desaparecer, de la mente de muchos alemanes, la imagen del «judío de la puerta de al lado», conocido, cercano y considerado hasta ese momento como un alemán más: "El otro", como categoría abstracta simplemente, no tiene nada que ver con "el otro" que yo conozco» (Bauman, 1997: 245).

Bauman (2007: 33; 2005c: 145-152) muestra su preocupación por el hecho de que, en un mundo en el que la diversidad y la pluralidad de sistemas de 
valores y estilos de vida se ha convertido en experiencia cotidiana, de la que no podemos sustraernos, la mixofobia, entendida como la propensión a rehuir de la diversidad y la diferencia buscando espacios de semejanza e igualdad, pueda convertirse en la estrategia dominante a la hora de afrontar las consecuencias de esa diversidad. Ya no es posible entender la comunidad como mismidad, como «ausencia del Otro, especialmente de otro obstinadamente diferente» (Bauman, 2003b: 137). Si, durante la mayor parte de la historia de la humanidad, proximidad física y proximidad social aparecían fuertemente correlacionadas, hoy esta correlación se ha roto y el extraño aparece como símbolo de esta ruptura:

Durante gran parte de la historia de la humanidad, la proximidad física se traslapó con la proximidad social o, al menos, tuvo una correlación cercana [...] Un forastero podía entrar en el radio de proximidad física únicamente en una de tres categorías: como enemigo al que había que combatir y expulsar, como un invitado admitido temporalmente al que se confinaba a un espacio especial y a quien la estricta observancia del ritual de aislamiento volvía inocuo, o como un futuro vecino, en cuyo caso se lo debía hacer parecido a un vecino, esto es, se lo hacía comportarse como tal [...]. [Hoy] surge una situación totalmente nueva al romperse la coordinación entre proximidad física y social / cognitiva. Los forasteros aparecen físicamente dentro de los confines del mundo en que se vive. La extrañeza de los extraños deja de ser una ruptura temporal de la norma y un motivo de irritación curable. Los extraños permanecen y se niegan a irse —aunque, en el fondo, se espera que, a la larga, lo hagan—, mientras, tercamente, escapan a la red de reglas locales y siguen permaneciendo extraños. (Bauman, 2004a: 171-173)

De ahí la caracterización que Bauman (2004a: 175) hace de esos extraños, combinando de manera paradójica las características del vecino y del forastero: «Extraños; socialmente distantes aunque físicamente cerca. Forasteros dentro de nuestro alcance físico. Vecinos fuera del alcance social». ¿Qué problema plantean estos extraños? «El Extraño hace pedazos la roca sobre la que descansa la seguridad de la vida cotidiana» (Bauman, 2001: 19). No es en esto diferente del extranjero o del forastero: por vivir entre dos culturas o dos mundos sociales, ninguno de ellos asume las normas de la sociedad de acogida con la «naturalidad» de los nativos. Y, al igual que ocurre con la acusación de dudosa lealtad hacia el forastero o de objetividad crítica hacia el extranjero, considera que «el cargo más serio de la comunidad nativa contra el extraño [sea] su predisposición objetivista (desarraigada, cosmopolita o completamente ajena)» (Bauman, 2005a: 116).

Pero, a diferencia de esas otras dos categorías, la consideración de extraño puede mantenerse (o aparecer) a pesar de que el sujeto así considerado realice el máximo esfuerzo por integrarse en la norma social dominante, hasta el punto de que «aunque intentara por todos los medios, y con éxito, comportarse aparentemente del modo que exige esa norma, el grupo no daría crédito a la existencia de reciprocidad entre su punto de vista y el del grupo» (Bauman, 2001: 19). A diferencia de lo que ocurre con el forastero, que deja de serlo si el 
proceso de adaptación o ajuste social al endogrupo tiene éxito (Schütz, 2003: 107), el extraño está condenado a serlo para siempre, con independencia del esfuerzo que haga por adaptarse: «No es suficiente mostrar una nueva actitud. El extraño no puede dejar de ser extraño. [...] Lo más que pueda llegar a ser es un antiguo extraño, es ser "un amigo a prueba" y en permanente verificación, una persona sometida a vigilante observancia y bajo la presión constante de ser alguien que no es, avergonzado de su culpabilidad por no ser lo que debe ser» (Bauman, 2005a: 108). Es esta permanencia en la situación de otredad la característica más distintiva del extraño y lo que explica que cualquiera, forastero, extranjero o vecino, pueda, en determinadas circunstancias, verse convertido en un extraño. La misma persona que hasta ayer era un forastero que se esforzaba meritoriamente para ser aceptado o al menos tolerado por el grupo al que se aproxima (Schütz, 2003: 95), o un extranjero que «en las relaciones más íntimas de persona a persona [...] puede desplegar todo género de atractivos y excelencias» (Simmel, 1977: 718), puede verse convertido, de la noche a la mañana, en un extraño, en alguien que ya no encaja en el mapa cognitivo moral o estético del mundo (Bauman, 2001: 27). En palabras de Beck (2000: 129):

La categoría de extraño rompe desde dentro con las categorias y los estereotipos del mundo de los del lugar. Los extraños no encajan en ninguno de los moldes en los que deberían encajar. Y ésta es la causa, precisamente, de una fuerte irritación. Porque, dicho de otra forma, extraño es lo que queda excluido de acuerdo con los estereotipos de un determinado orden social [...] Pero son nativos de primera o segunda generación, son del lugar, aunque los del lugar los excluyan como extraños. (La cursiva es nuestra)

El extraño lo es no por sus propias características, sino en función de una determinada definición de orden social que incluye tanto como excluye a determinados sujetos o grupos: la aparición del extraño es consecuencia inevitable de los proyectos de ordenamiento social (Bauman, 2001: 20). Es lo que Bauman denomina la «actitud del jardinero» (1997: 75) o, directamente, la «práctica del Estado jardinero» (2005a: 51): cuando diseñamos un orden social más «integrado», descubrimos en mayor medida elementos que no encajan en nuestro diseño. De esta manera, la figura del extraño, «que no es solo el "desconocido", sino el ajeno, el que está "fuera de lugar"», se transforma en una amenaza (Bauman, 2003a: 137). La duda está en cómo actuar ante esta amenaza.

Según Lévi-Strauss (1955: 464), a lo largo de su historia, la humanidad ha recurrido a dos estrategias para enfrentarse a la otredad: la antropoémica y la antropofágica. La estrategia antropofágica o de asimilación busca «aniquilar a los extraños devorándolos, para transformarles después metabólicamente en un tejido indistinguible del propio». Por su parte, la estrategia antropoemética o de exclusión consiste en «vomitar a los extraños, desterrarlos fuera de los confines del mundo ordenado y prohibirles toda comunicación con quienes permanecían dentro" (Bauman, 2001: 28-29). Ambas estrategias continúan dominando las políticas de gestión de la inmigración en las sociedades actuales: 
la antropoémia se refleja en la persecución y expulsión de los inmigrantes tipificados como «ilegales» o «sin papeles»; la antropofagia en los discursos que cuestionan el multiculturalismo, considerándolo un fracaso, y proponen una vuelta a políticas asimilacionistas más estrictas.

Bauman relaciona ambas estrategias con dos modelos de construcción del estado moderno y sus correspondientes concepciones de la ciudadanía: el modelo liberal republicano y el «nacionalista-racista». El primer modelo reconoce las diferencias en las tradiciones culturales de las personas y confía en que estas diferencias, en la medida en que son un producto de la socialización, sean flexibles, remodelables y, en última instancia, reconducibles a un espacio identitario compartido: éste ha sido el ideal francés de integración republicana. El segundo de los modelos, por el contrario, sostiene que la integración cultural siempre será limitada y, en algunos casos, imposible: «Hay determinadas personas a las que nunca se convertirá en otra cosa que lo que son. Por así decirlo, no tienen remedio. Uno no puede librarlas de sus defectos; uno solo puede librarse de ellas mismas, con sus correspondientes excentricidades y maldades innatas y eternas» (Bauman, 2001: 29). Este planteamiento subyace tanto a la reflexión de Huntington (2004) sobre las supuestas dificultades para la americanización de la inmigración hispana como a la idea de Sartori (2003) de que existen inmigrantes inintegrables.

Bauman considera que ninguna de esas estrategias funciona en la actualidad, pues sólo tenían sentido cuando era posible distinguir con claridad entre el afuera y el adentro de un determinado territorio, algo imposible en el escenario de la globalización actual. Esta imposibilidad, tanto de expulsar masivamente como de asimilar plenamente al otro, explicaría la tendencia actual de intentar contener a las personas inmigrantes fuera de las fronteras de las sociedades más desarrolladas. Pero esta estrategia también está condenada al fracaso, ya que "en el mundo moderno, los extraños son ubicuos e irremovibles» (Bauman, 2004a: 187). Prueba de este fracaso es la proliferación, junto a todas las fronteras, de campos de refugiados y centros de internamiento supuestamente provisionales que acaban por configurar una situación de provisionalidad duradera o de transitoriedad congelada (Bauman, 2004b: 146). Cuando esto ocurre, el extraño, a diferencia del extranjero o del forastero, ya no es un recién llegado en proceso de ajuste o de integración, sino que se convierte en «un vagabundo eterno, siempre y en todas partes carente de hogar, sin esperanza de "llegar" alguna vez" (Bauman, 2005a: 116). No deberían estar aquí, no encajan, están de sobra, pero no hay forma de deshacerse de ellos. «Forasteros absolutos, forasteros en todas partes y fuera de lugar en todas partes salvo en lugares que están ellos mismos fuera de lugar» (Bauman, 2005b: 106). Inasimilables e incontrolables, el problema que plantean es que «traspasarán las fronteras con independencia de que se les invite o no a hacerlo. Controlan su propio emplazamiento y, por consiguiente, se mofan de los esfuerzos de los buscadores de pureza por "colocar las cosas en su sitio" y terminan por poner al descubierto la fragilidad y la inestabilidad irremediables de todas las disposiciones» (Bauman, 2001: 15). 
En estas circunstancias, las metáforas biológicas colonizan el lenguaje social y político (Bauman, 2005a: 77-78). Conceptos como los de impureza, contaminación, corrupción o suciedad son profusamente utilizados para describir la situación. «El Extraño — recuerda - es la personificación misma de este tipo de suciedad. No es de extrañar que los habitantes autóctonos de todas las épocas y lugares, en sus frenéticos esfuerzos por apartar, confinar, exiliar o destruir a los extraños, compararan el objeto de sus sudores con parásitos y bacterias» (Bauman, 2001: 19). La deshumanización del extraño lo sitúa en los umbrales de la animalidad: "Las cucarachas, las moscas, las arañas o los ratones, que pueden decidir en cualquier momento compartir un hogar con sus residentes legales (humanos) sin pedir permiso a los propietarios, constituyen, por este motivo, siempre, potencialmente, huéspedes no invitados y, por ello, no cabe incorporarlos a ningún esquema imaginable de pureza» (Bauman, 2001: 15). Cuando esto sucede, nos encontramos ante un nuevo límite cuya superación nos lleva hasta el extremo del espacio de la distancia social:

Sin embargo, algunos extraños no son sobre los que aún no se decide; son, en principio, indecidibles. Son la premonición de un "tercer elemento", que no debería existir. Son los verdaderos híbridos, los monstruos — no sólo inclasificados, sino inclasificables. Ellos no sólo cuestionan la oposición, el principio como tal, la plausibilidad de la dicotomía que las oposiciones sugieren y la posibilidad de la separación que demandan. Desenmascaran la frágil artificialidad de la división. Destruyen el mundo. Llevan al extremo la inconveniencia temporal del «no saber cómo continuar» hasta conducir a una parálisis terminal. Por eso son "tabuizados», desarmados, suprimidos, exiliados física o mentalmente — de lo contrario, el mundo podría perecer. (Bauman, 2005a: 91)

El extraño pierde definitivamente cualquier relación con categorías fundadas sobre elementos más o menos contrastables — nada tiene que ver con el vecino, el forastero o el extranjero-, hasta acabar convertido en la manifestación más extrema de la otredad: el monstruo.

\section{Monstruos}

Durante una conferencia en la Casa de América de Madrid, Touraine (2008) reflexionaba sobre la existencia de matrimonios mixtos y decía: «Esa es la mejor prueba de que la inmigración no es ningún monstruo. Las culturas diferentes pueden convivir». Touraine no habla simplemente de convivencia entre diferentes, sino de mezcla, de hibridación. ¿'No es esto lo que aterra del monstruo, su capacidad de introducirse de manera plena en nuestras vidas, modificándolas? ¿Y si fuera precisamente esa mixticidad cultural la que hace que determinadas personas sean categorizadas como «monstruos»?

Según Graham (2002: 11), la cultura occidental está atravesando una profunda crisis de la idea de "singularidad humana» (buman uniqueness), caracterizada en términos de «emborronamiento de los límites», de «disolución de la higiene ontológica», mediante la cual nuestra cultura ha trazado, a lo largo 
de los últimos tres siglos, las líneas de corte que separan a los seres humanos de la naturaleza y de las máquinas. Una de las formas esenciales en la que se ha afirmado (y modificado) la frontera entre humanos y «casi-humanos» es a través del discurso de la monstruosidad (Richards, 1994: 377). Considerados como criaturas que "surgen al margen del curso de la Naturaleza» (Graham, 2002: 49; Choza, 2008: 79), los monstruos cumplen una función demarcadora entre lo normal y lo desviado. Precisamente por lo que tiene de diferenciación patológica respecto de una supuesta norma de la naturaleza, el monstruo es necesario para sostener una perspectiva armónica sobre la realidad, incluyendo los cambios experimentados por ésta:

La proliferación de monstruos sin futuro es necesaria para que se pueda redescender del continuo al cuadro a través de una serie temporal [...] El monstruo asegura, en el tiempo y con respecto a nuestro saber teórico, una continuidad que los diluvios, los volcanes y los continentes hundidos mezclan en el espacio para nuestra experiencia cotidiana. La otra consecuencia es que, a lo largo de una historia tal, los signos de continuidad no pertenecen más que al orden de la semejanza. (Foucault, 1984: 156)

El monstruo traza el límite de las diferencias normales, aquellas que no se alejan demasiado de la norma: «El monstruo es la cepa de la especificación, pero ésta no es más que una subespecie en la lenta obstinación de la historia» (Foucault, 1984: 157). Desde esta perspectiva, la figura del monstruo se relaciona con la del salvaje, quien cumplía en la Edad Media la misma función demarcadora: «La época medieval había prohijado a un hombre salvaje que, fuese como etapa de sufrimiento y penitencia o como realidad monstruosa, proporcionaba a la sociedad un modelo anormal, por decirlo así, de comportamiento" (Bartra, 1996: 291). A su vez, este hombre salvaje se identifica en muchas representaciones medievales con el bárbaro (Droit, 2009: 190)ํ․ En el mundo antiguo, el bárbaro, el salvaje y el monstruo se caracterizan por llevar una vida de intemperancia y desmesura, sin normas ni límites, que suele definirse con el término griego hybris (Droit, 2009: 50-51).

Aunque, generalmente, los monstruos habitaban en los confines de la geografía conocida, con lo cual marcaban el umbral entre el mundo civilizado y el desconocido (Graham, 2002: 51), Eco recuerda en su Historia de la fealdad que, en la Edad Media, estos personajes formaban parte de la vida cotidiana y cumplían una función terapéutica o salvífica (citado en Serrano, 2010: 78); su aparición era un signo de insatisfacción de Dios con el comportamiento de los hombres y una advertencia para modificarlo (Brammall, 1996: 12). La modernidad, con su desencantamiento del mundo, cambia radicalmente el papel que desempeña el monstruo: «Una forma de concebir lo moderno es

3. Todorov (2008: 35) ofrece una interesante aunque bien diferente aproximación al bárbaro, según la cual éste es aquél que, por juzgar a otros tan radicalmente diferentes de sí, los trata "como no humanos, como monstruos y como salvajes». Bárbaro es quien define y trata a otros como «bárbaros». 
precisamente aquel universo donde ya no hay monstruos, sino solo humanos, donde lo fantástico y lo extraordinario, lo otro y lo ajeno, es expulsado» (Serrano, 2010: 79). Pero esta realidad plenamente «normalizada» es una aspiración imposible: la diferencia, la extrañeza, la desviación no dejan de estar presentes en todas las sociedades; esto es así porque, como señala Erikson (1966: 11), «la aberración no es algo inherente a algunas formas de comportamiento, sino algo atribuido a las mismas por el público que, directa o indirectamente, las contempla». En palabras de León (2009: 83): «la "monstriparidad”, o el parir monstruos, es una tendencia inserta en la organización misma de la socialidad».

De esta manera, con el término monstruo ocurre lo mismo que con el de bárbaro: no es tanto un concepto cuanto "una máquina para fabricar lo exterior», un operador, es decir, un elemento cuya función es la de «separar a un grupo y los que son sus otros, la función de construir un fuera y un dentro, de crear un centro y unos confines periféricos» (Droit, 2009: 121). La barbarie hace siempre referencia «a la in-cultura del prójimo» (Fernández Buey, 1995: 33; Santamaría, 2002b: 60). Tanto las sociedades tradicionales como las modernas practican este ejercicio de atribución, que cumple funciones imprescindibles para la construcción y el mantenimiento del orden social:

Las comunidades humanas necesitan poder analizar y prever las zonas de experiencia situadas inmediatamente fuera de sus límites: los peligros invisibles que, en todas las culturas y en todas las épocas, parecen amenazar su seguridad. El folklore tradicional imagina demonios, diablos, brujas y malos espíritus, tal vez como medio para encarnar estos peligros que, de lo contrario, serían informes; pero el aberrante es otra especie de recordatorio. En su calidad de transgresor de las normas, representa a las fuerzas agazapadas fuera de las fronteras del grupo: así, informa a sus miembros de cómo es el mal y de la apariencia que puede asumir el diablo. Y con ello señala las diferencias existentes entre el interior y el exterior del grupo. Pudiera ser muy bien que sin este drama representado en los «arrabales» del espacio social, la comunidad carecería del sentido interior de identidad y cohesión, y no tendría conciencia de los contrastes que le confieren la naturaleza de entidad diferenciada en un espacio concebido a escala mundial. Por consiguiente, la aberración no puede definirse únicamente como una conducta que altera la estabilidad en la sociedad, sino que, debidamente controlada, puede desempeñar una importante función de mantenimiento de esta misma estabilidad. (Erikson, 1966: 15-16)

Encontramos aquí la ambigüedad esencial del monstruo: cumple la función de señalar los límites entre lo normal y lo patológico, pero también la de desvelar la fragilidad de estas categorías, que damos por supuestas. Los monstruos se sitúan en las "puertas de la diferencia» (Cohen, 1996: 7), «en la entrada a lo desconocido, actuando como porteros o guardianes de lo aceptable» (Graham, 2002: 53). Su sola existencia desanima a quienes se sientan tentados de adentrase en su territorio. Pero los monstruos «sirven tanto para marcar las líneas de corte [entre humanos y no humanos] como, subversivamente, para señalar la fragilidad de tales fronteras» (Graham, 2002: 12). En este sentido, 
«el monstruo no es meramente lo opuesto a lo idéntico, no es simplemente una inversión [...] La monstruosidad indica el final de las delimitaciones claras, un mestizaje caótico de categorías que, en pleno proceso de confusión, nos advierten de que su ordenamiento está muy lejos de ser inevitable» (Graham, 2002: 54). Recordemos el análisis de Bauman sobre el deslizamiento de algunos extraños hacia la categoría de monstruos. Los monstruos simbolizan una grieta en una categorización que pensábamos y queríamos inviolable; por eso Graham (2002: 39) destaca su capacidad para «desestabilizar nuestras certidumbres axiomáticas», y es en esta capacidad donde reside su horror. Esta capacidad del monstruo para emborronar la supuesta claridad de las delimitaciones que organizan nuestra relación con los otros lo sitúa en el espacio de los otros inapropiados e inapropiables de los que habla Haraway: «Ser inapropiado/ ble es no encajar en la taxón, estar desubicado en los mapas disponibles que especifican tipos de actores y tipos de narrativas» (1999: 126). Habitan mundos en los que las fronteras entre las identidades y los espacios se interpenetran, lo cual permite la emergencia de sujetos y mundos inesperados.

Como hemos señalado, en la antigüedad los monstruos compartían el mundo cotidiano con los seres humanos, su naturaleza anormal era compatible con su existencia normal: «Los monstruos premodernos están insertos, más allá de que representen el mal o la deformidad, en un marco y en un relato general [que] hacen tolerable el terror que pueda producir el monstruo. Producen cierto temor o repugnancia según los casos, pero no producen angustia. Generan asco, pero no la oscura inquietud de lo que llamamos "inquietante" y de lo siniestro" (Serrano, 2010: 79). Esta situación se invierte con la modernidad: si, por un lado, dentro del «universo cartesiano de lo moderno, aparentemente el monstruo deja de tener realidad, deja de cumplir función, deja de convivir y de existir propiamente», por otro, en ese mismo universo, emerge una nueva realidad que Freud denominará Unheimlich y que caracteriza a los terrores modernos:

Se trata de una realidad extraña y a la vez familiar, desconocida y próxima, y que por eso mismo nos inquieta especialmente, nos saca de nuestra confianza básica en el entorno, nos produce un constante desasosiego que no sabemos ni podemos concretar. Esto es lo específicamente moderno, el atributo que acompaña invariablemente y por definición al monstruo moderno, que no es ya múltiple en sus funciones, que de hecho carece ya de función en el sentido apuntado para el monstruo antiguo y medieval, pero cuyo rasgo común es lo inquietante. De modo que si el mundo moderno ha generado muchos monstruos, todos ellos parecen ser variantes de uno y el mismo monstruo, que no es siquiera el diablo, que no es sin más el mal o el extraño, que es lo inquietante, lo que a la vez resulta familiar y amenazante, lo que por definición impide cualquier quietud. [...] La mayor parte de los monstruos de la modernidad tienen como característica fundamental su proximidad asfixiante, bien por su emergencia del propio interior del individuo o de la casa, o bien por ser parte o creación de quien los padece y de aquellos a quienes atemoriza. Todos ellos acechan como una sombra tras lo más familiar o subyacen como sustrato de uno mismo. (Serrano, 2010: 81) 
Otra de las características más inquietantes del monstruo es su capacidad para generar sentimientos contradictorios: puede ser al mismo tiempo «aborrecible y atractivo" (Graham, 2002: 53). Lo mismo ocurre con los bárbaros, que, a pesar de todo, «fascinan» (Kristeva, 1991: 66). El monstruo sintetiza el tabú y el deseo, los límites y su transgresión, son repulsivos y fascinantes a la vez: «Los monstruos simbolizan, entonces, no el otro opuesto sólidamente encerrado tras sus propios límites, sino la otredad de unos mundos posibles, de posibles versiones de nosotros mismos, no realizadas aún» (Shildrick, 1996: 8 ). Esto es algo que se refleja perfectamente en el relato del Dr. Jeckyll (el monstruo está dentro de nosotros, pugnando por liberarse) o en las versiones más modernas del mito vampírico (asociadas cada vez más explícitamente al erotismo, la sexualidad o el romance adolescente).

Como señala Droit (2009: 230), para las sociedades antiguas, los bárbaros (o, para el caso, los monstruos) «o bien lo seguían siendo para siempre, sin por ello ser inhumanos, o bien podían mejorar, desde el punto de vista cultural, educativo, político y de civilización, helenizándose —o romanizándose». En cambio, para los modernos, el problema consiste en que «el civilizado siempre puede, súbitamente, transformarse en bárbaro». Con otras palabras, el problema esencial no es que el Otro siga siendo otro, ni que deje de serlo mediante su integración plena en nuestra cultura; el problema fundamental lo tenemos con aquel Otro que se mezcla sin perder elementos significativos de su identidad:

Los nuevos odios del presente ya no surgen principalmente de un conocimiento antropológico supuestamente fiable sobre la identidad estable y la diferencia predecible del Otro. Sus fuentes novedosas se encuentran en el problema que nace cuando no somos capaces de localizar la diferencia del Otro dentro del léxico de sentido común de la alteridad. Las personas diferentes aún son odiadas y temidas, pero la antipatía real hacia ellas no es nada en comparación con los odios dirigidos hacia la amenaza más grande que representan los mediodiferentes o parcialmente conocidos. Haberse mezclado supone haber tomado parte en una gran traición civilizacional. Cualquier rastro desconcertante del híbrido resultante debe, por tanto, eliminarse de las zonas ordenadas y desinfectadas de la imposible cultura pura. (Gilroy, 2008: 226)

Frente al planteamiento de Touraine, el otro-monstruo sería aquel que muestra mayor capacidad de mestizaje y de mezcla, de manera que "gran parte de las veces, la rabia y el odio que promueven los racismos pueden incluso provenir de los éxitos modestos que derivan de los intentos de compartir «los valores y el estilo de vida» a través de las barreras permeables de la raza y la etnicidad absoluta» (Gilroy, 2008: 263). Este rechazo de la hibridación cultural es la base del denominado "nuevo racismo", ese racismo heterófilo que elogia la diferencia cultural, empezando por la propia, pero sólo para hacer apología de las «raíces», de su esencia irreductible y de las bondades del "desarrollo separado» de las culturas (San Román, 1996: 31; Solana, 2000: 101-102), un racismo diferencialista que proclama, por encima de todo, «el carácter nocivo de la cancelación de las fronteras» (Fernández Buey, 1995: 245). Y es aquí 
donde conceptos como los de contagio, suciedad o impureza adquieren toda su importancia.

Ya lo hemos visto anteriormente: la pureza es la otra cara de la unidad y la «unicidad» (Crook, 1998: 537). La suciedad es, siempre y necesariamente, «el producto secundario de una sistemática ordenación y clasificación de la materia, en la medida en que el orden implica el rechazo de elementos inapropiados» (Douglas, 1973: 54-55). Cuanto más ordenamos, más desorden descubrimos; cuanto más limpiamos, más suciedad encontramos, ya que "cualquier sistema dado de clasificación tiene por fuerza que provocar anomalías» (Douglas, 1973: 59). Pero esta aspiración a la pureza, al orden, a la coherencia, se demuestra imposible: «La paradoja final de la búsqueda de la pureza reside en su intento de obligar a la experiencia a que entre dentro de las categorías lógicas de la no contaminación. Pero la experiencia no es fácil de manejar y quienes lo intentan se ven inmersos en contradicción» (Douglas, 1973: 216-217). Pese a todo, seguimos intentándolo. De ahí la proliferación de fronteras, prohibiciones y tabús que aspiran a mantener "puro" el orden social. Y esto es algo que no ocurre solo en pueblos "primitivos» como los estudiados por Douglas, sino también en nuestras sociedades modernas (Lévy, 1996; Mann, 2009). Esta mirada incesantemente incómoda está en el origen de lo que Appadurai (2006) denomina "ansiedad de incompletud» (anxiety of incompleteness), que hace que identidades mayoritarias se transformen en identidades predadoras, empeñadas en la eliminación de las minorías, consideradas un inaceptable recordatorio de la imposibilidad de constituirse como una totalidad homogénea.

El monstruo es ese otro capaz de atravesar las fronteras, de desobedecer las prohibiciones y de incumplir los tabús, que quiere mezclarse, mestizarse, hibridarse, y, al hacerlo, amenaza con disolver las distinciones que creíamos y queríamos claras. Se convierte, así, en un agente contaminante, pues, como dice Douglas (1973: 154): «una persona contaminadora siempre está equivocada. Ha desarrollado alguna condición errónea o atravesado sencillamente alguna línea que no debe cruzarse y este desplazamiento desencadena el peligro para alguien». Y esto es así independientemente de la voluntad o las intenciones de esa persona.

Desde esta perspectiva, muchas veces, el otro-inmigrante se presenta como un ser liminal, topológicamente ambiguo, tanto allí como aquí (¿̇más allí que aquí?); alienígenas procedentes de otros mundos, trasuntos de aquellos extraterrestres que, en el clásico de ciencia ficción La invasión de los ladrones de cuerpos, hacían gritar a su protagonista: «YYa están aquí! ¡Los tenemos entre nosotros!» (Delgado, 2009: 14).

\section{Conclusión}

Como advierte Sayad (2010: 304), la clasificación es una lucha en la que los individuos y los grupos se juegan "todo su ser social, todo lo que define la idea que se hacen de sí mismos, todo ese impensado social por el que se constituyen como "nosotros" por oposición a "ellos", a "otros", y al que se mantienen suje- 
tos por una adhesión casi corporal». Este es el peligro de las categorizaciones: caer en la actitud textual, es decir, "preferir la autoridad esquemática de un texto a los contactos humanos que entrañan el riesgo de resultar desconcertantes» (Said, 2003: 135).

Todas las sociedades, más allá de referencias abstractas a la inmigración o a los inmigrantes, construyen esquemas típico-ideales que diferencian entre categorías de inmigrantes según una supuesta afinidad o distancia sociocultural con la sociedad receptora. Esta categorización se desarrolla en un escenario caracterizado por una distribución asimétrica de poder, donde unos (la población autóctona) definen y otros (las personas inmigrantes) son definidos. La perspectiva política que subyace a la idea de inmigración elegida es la mejor expresión de esa asimetría en la capacidad de construir la diferencia etnocultural (Carens, 2002; Solana, 2009). Nos encontramos ante una perspectiva y un discurso que construyen la diferencia cultural mediante un doble movimiento: por un lado, atribuyendo a los inmigrantes determinadas características supuestamente compartidas por quienes tienen un mismo origen nacional; por otro, contrastando esas características atribuidas con una igualmente supuesta identidad colectiva propia de la sociedad receptora (Roiz, 1994; De Lucas, 2002; Pajares, 2005; Zamora, 2012). Al fin y al cabo, como señala De Lucas (2009: 215), "nuestra mirada es un instrumento de la teogonía social, de la forma que construimos y organizamos el mundo ( $\mathrm{y}$ a los otros) por referencia a nuestra propia imagen".

El resultado de esa organización del mundo y de los otros es una jerarquización de las personas inmigrantes en función de su mayor o menor proximidad a nuestra supuesta identidad etnocultural. A partir de esta operación de categorización, «algunos inmigrantes (más unos que otros) pasan a conceptualizarse como "culturalmente incompatibles"” (Cea d'Ancona, 2009: 18). De esta manera, las relaciones entre la población autóctona y las personas inmigrantes tienen lugar en el marco de una categorización, no siempre explícita, que opera configurando una «escala de distancia social» que diferencia entre inmigrantes más o menos cercanos a la cultura de la sociedad receptora en función de sus distintos orígenes nacionales y de las adscripciones culturales supuestamente derivadas de tales orígenes.

Son muchas las investigaciones que descubren que, entre la población española, se dan opiniones, actitudes y comportamientos claramente diferenciados dependiendo de las características étnicas, culturales y socioeconómicas de las personas inmigrantes (Cea d'Ancona, 2009; Cea d'Ancona y Valles, 2010; Colectivo Ioé, 2003, 2009; Aierdi y Moreno, 2011). En un artículo de 1993, el Colectivo Ioé señalaba que, en su actitud ante la inmigración, la sociedad española manejaba una suerte de «escala de Otros, ante los que se adoptan actitudes diferenciadas», de manera que "a medida que el grupo se aproxime a la raza blanca, a la cultura occidental y a la religión cristiana, la tolerancia -incluso la franca acogida - aumenta»; por el contrario, "distanciarse de alguno de estos parámetros es empezar a caer en desgracia, aún siendo ciudadano español, como se constata en el caso de la etnia gitana» (Colectivo Ioé, 1993: 73). 
En la literatura académica sobre la inmigración, se recurre en muchas ocasiones a Simmel y, en menor medida, a Schütz, como perspectivas teóricas para el análisis de los procesos de construcción de la otredad; sin embargo, no es habitual relacionar estas aportaciones clásicas con otras más recientes, como las de Bauman, Beck, Graham o Douglas. En este artículo, hemos recurrido a todo ese corpus teórico con el objetivo de cartografiar un mapa de distancia social que recoja, desde una perspectiva típico-ideal, los distintos imaginarios que una población autóctona puede proyectar sobre las personas inmigrantes. Consideramos que esta propuesta de mapeo conceptual puede contribuir a iluminar y comprender teóricamente el complejo campo de las relaciones entre inmigrantes y autóctonos, donde se combinan procesos objetivos y dinámicas subjetivas en la construcción de imágenes del otro-inmigrante que tienen consecuencias prácticas evidentes. Porque, si pensamos en términos de esa posible «escala de Otros» a la que se refería el Colectivo Ioé, no es lo mismo ser mirado o definido como inmigrante-forastero, como inmigrante-extranjero, como inmigrante-extraño o como inmigrante-monstruo.

\section{Referencias bibliográficas}

Aguiluz, Maya (2009). El lejano próximo: Estudios sociológicos sobre extrañeidad. Barcelona: Anthropos.

Aierdi, Xabier y Moreno, Gorka (2011). «Discriminación percibida por el colectivo inmigrante y grado de simpatía de la población autóctona: ¿¿ara y cruz de una misma moneda?». Documentación Social, 162, 79-116.

Alcalde, Rosalina (2011). «De los outsiders de Norbert Elias y de otros extraños en el campo de la sociología de las migraciones». Papers, 96 (2), 375-387.

Alexander, Jeffrey C. (2004). «Rethinking Strangeness: From Structures in Space to Discourses in Civil Society». Thesis Eleven [en línea], 79, 87-104. $<$ http://dx.doi.org/10.1177/0725513604046959>.

Anderson, Benedict (2006). Comunidades imaginadas: Reflexiones sobre el origen y difusión del nacionalismo. México: Fondo de Cultura Económica.

Appadurai, Arjun (2006). Fear of Small Numbers: An Essay on the Geography of Anger. Durham y Londres: Duke University Press.

BARTRA, Robert (1996). El salvaje en el espejo. Barcelona: Destino.

- (2008). Culturas líquidas en la tierra baldía: El salvaje europeo. Buenos Aires: Katz.

Bauman, Zygmunt (1997). Modernidad y Holocausto. Madrid: Sequitur.

- (2001). La postmodernidad y sus descontentos. Madrid: Akal.

- (2002). Modernidad líquida. Buenos Aires: Fondo de Cultura Económica.

- (2003a). Comunidad: En busca de la seguridad en un mundo hostil. Madrid: Siglo XXI.

- (2003b). «Individualmente pero juntos». En: Beck, Ulrich y Beck-Gernsheim, Elisabeth. La individualización. Barcelona: Paidós, 19-26.

- (2004a). Ética posmoderna. Buenos Aires: Siglo XXI.

- (2004b). La sociedad sitiada. Buenos Aires: Fondo de Cultura Económica.

- (2005a). Modernidad y ambivalencia. Barcelona: Anthropos.

- (2005b). Vidas desperdiciadas: La modernidad y sus parias. Barcelona: Paidós.

- (2005c). Amor líquido: Acerca de la fragilidad de los vínculos humanos. Buenos Aires: Fondo de Cultura Económica.

- (2007). Confianza y temor en la ciudad: Vivir con extranjeros. Barcelona: Arcadia. 
- (2010). Mundo consumo: Ética del individuo en la aldea global. Barcelona: Paidós.

Beck, Ulrich (2000). La democracia y sus enemigos. Barcelona: Paidós.

- (2007). "Cómo los vecinos se convierten en judíos: La construcción política del extraño en una era de la modernidad reflexiva». Papers, 84, 46-66.

BÉJAR, Helena (2005). «Bauman, Simmel y Freud: Tres visiones de la ambivalencia». En: AriÑo, Antonio. Las encrucijadas de la diversidad cultural. Madrid: CIS, 71-88.

Benhabib, Seyla (2005). Los derechos de los otros: Extranjeros, residentes y ciudadanos. Barcelona: Gedisa.

- (2006). Las reivindicaciones de la cultura: Igualdad y diversidad en la era global. Buenos Aires: Katz.

Berger, Peter L. y Kellner, Hansfried (1985). La reinterpretación de la sociología. Madrid: Espasa Calpe.

BernsteIn, Richard J. (1991). «Una revisión de las conexiones entre inconmensurabilidad y otredad». Isegoria [en línea], 3, 5-25. <http://dx.doi.org/10.3989/isegoria.1991.i3.364>.

Brammall, Kathryn M. (1996). «Monstrous metamorphosis: Nature, morality and the rethoric of monstrosity in Tudor England». Sixteenth Century Journal [en línea], XXVII (1), 3-21. $<$ http://dx.doi.org/10.2307/2544266>.

CACHón, Lorenzo (2008). La inmigración en la sociedad española. Barcelona: Bellaterra.

Carens, Joseph H. (2002). «Inmigración y justicia: ¿A quién dejamos pasar?». Isegoria, 26, 5-27.

Cea d’Ancona, M. a Ángeles (2009). «Filias y fobias ante la imagen poliédrica cambiante de la inmigración: Claves en la comprensión del racismo y la xenofobia». Revista del Ministerio de Trabajo e Inmigración, 80, 39-60.

Cea d’Ancona, M. a Ángeles y Valles, Miguel (2010). Xenofobias y xenofilias en clave biográfica. Madrid: Siglo XXI.

Chaouite, Abdellatif (1997). «L'étranger, une figure mouvante». Ecarts d'Identité, 81, 2-3.

Choza, Jacinto (1994). "El problema de la aceptación del extranjero». Revista de Estudios Políticos, 83, 191-199.

- (2008). «Fronteras geográficas, sociológicas y metafísicas». Revista CIDOB d'Afers Internacionals, 82-83, 77-92.

Clarke, Simon (2002). «On strangers: Phantasy, terror and the human imagination». Journal of Human Rights [en línea], 1 (3), 345-355. <http://dx.doi.org/10.1080/14754830210156580>.

Cohen, Jeffrey (ed.) (1996). Monster Theory: Reading Culture. Minneapolis: University of Minnesota Press.

Cohen, Ted (2011). Pensar en los otros: Sobre el talento para la metáfora. Barcelona: Alpha Decay.

Colectivo Ioé (1993). «Hacia un análisis sociológico de la inmigración: Extranjeros en la Comunidad de Madrid». Politica y Sociedad, 12, 61-77.

- (2003). Experiencias de discriminación de minorias étnicas en España [en línea]. Viena: European Monitoring Centre on Racism and Xenophobia. <http://www.colectivoioe.org/uploads/edb969a5b5bb4f6aaf3f9afb865cf396533d9315.pdf> [Consulta: 29 abril 2014].

- (2009). Motivos de discriminación en España: Estudio exploratorio [en línea]. Madrid: Dirección General contra la Discriminación. Ministerio de Igualdad. <http://www.colectivoioe.org/uploads/69357c3b95b7ed349fb34bd8866f37e18c e01c2b.pdf> [Consulta: 29 abril 2014]. 
Collier, Mary Jane (ed.) (2001). Constituting cultural difference through discourse. Londres: Sage.

Crook, Stephen (1998). "Minotaurs and Other Monsters: "Everyday Life" in Recent Social Theory». Sociology [en línea], 32 (3), 523-540. <http://dx.doi.org/10.1177/0038038598032003007>.

Delphy, Christine (2008). Classer, dominer: ¿Qui sont les «autres»? París: La Fabrique.

Delgado, Manuel (2009). «Seres de otro mundo: Sobre la función simbólica del inmigrante». En: Mellado, Yago (coord.). La dinámica del contacto: Movilidad, encuentro y conflicto en las relaciones interculturales. Barcelona: CIDOB, 13-22.

Douglas, Mary (1973). Pureza y peligro: Un análisis de los conceptos de contaminación y tabú. Madrid: Siglo XXI.

Droit, Roger-Pol (2009). Genealogía de los bárbaros. Barcelona: Paidós.

Elias, Norbert (2003). «Ensayo teórico acerca de las relaciones entre establecidos y forasteros». Revista Española de Investigaciones Sociológicas, 103, 213-251.

Erikson, Kai T. (1966): "Notas sobre la sociología de la aberración». En: Becker, Harold S. (comp.). Los «otros» entre nosotros: Perspectivas sobre la aberración. Barcelona: Sagitario.

Fernández Buey, Francisco (1995). La barbarie: De ellos y de los nuestros. Barcelona: Paidós.

FICHET, Brigitte (1993). «Étranger et immigré: Deux termes problématiques». Revue de Sciences Sociales de la France de L'Est, 112-117.

Foucault, Michel (1984). Las palabras y las cosas. Barcelona: Planeta-Agostini.

Gallego, Carmen (2000). «Extranjeros y ciudadanos, ¿¿dos categorías antagónicas?». Temas de Antropología Aragonesa, 10, 161-178.

Germanin, Annick (1997). "L'étranger et la ville». Revue Canadienne des Sciences Regionales, XX (1), 237-254.

Gilroy, Paul (2008). Después del imperio. Barcelona: Tusquets.

Graham, Elaine. L. (2002). Representations of the Post/Human: Monsters, Aliens and Others in Popular Culture. New Jersey: Rutgers University Press.

Haraway, Donna (1999). «Las promesas de los monstruos: Una política regeneradora para otros inapropiados/bles». Politica y Sociedad, 30, 121-164.

Huntington, Samuel P. (2004). ¿Quiénes somos?: Los desafios a la identidad nacional estadounidense. Barcelona: Paidós.

Kapuścínski, Ryszard (2007). Encuentro con el Otro. Barcelona: Anagrama.

Kristeva, Julia (1991). Extranjeros para nosotros mismos: ¿Será posible la convivencia multirracial en la Europa del siglo XXI? Barcelona: Plaza \& Janés.

Lakoff, George y Ferguson, Sam (2007). «El marco conceptual de la inmigración». Sin Permiso [en línea], 7, octubre. <http://sinpermiso.info/textos/index.php?id=1433> [Consulta: 29 abril 2014].

León, Emma (2009). «El monstruo». En: León, Emma (ed.). Los rostros del Otro: Reconocimiento, invención y borramiento de la alteridad. Barcelona: Anthropos, 61-96.

LÉvy, Bernard-Henry (1996). La pureza peligrosa. Madrid: Espasa Calpe.

LÉvi-Strauss, Claude (1955). Tristes tropiques. París: Plon.

LuCAS, Javier de (2002). "Algunas propuestas para comenzar a hablar en serio de política de inmigración». En: LuCAS, Javier de y Torres, Francisco (eds.). Inmigrantes: ¿Cómo los tenemos? Madrid: Talasa, 23-48.

- (2009). «Discursos de lo invisible: Construir la presencia de los inmigrantes». En: VVAA. Los otros entre nosotros: Alteridad e inmigración. Madrid: Círculo de Bellas Artes, 214-231. 
Maffesoli, Michel (2004). El nomadismo: Vagabundeos iniciáticos. México: Fondo de Cultura Económica.

Mann, Michael (2009). El lado oscuro de la democracia. Valencia: Publicacions de la Universitat de València.

Martínez, Emilio (2000). «Robert E. Park y las migraciones». Scripta Nova [en línea], 75. <http://www.raco.cat/index.php/ScriptaNova/article/view/55356> [Consulta: 29 abril 2014].

Mclemore, S. Dale (1970). «Simmel's "Stranger": A Critique of the Concept». The Pacific Sociological Review [en línea], 13 (2), 86-94. <http://dx.doi.org/10.2307/1388311>.

Ono, Kent A. y Sloop, John M. (2002). Shifting borders: Rhetoric, immigration and California's Proposition 187. Filadelfia: Temple University Press.

PajAres, Miguel (2005). La integración ciudadana: Una perspectiva para la inmigración. Barcelona: Icaria.

PARK, Robert E. (1924). «The Concept of Social Distance as Applied to the Study of Racial Attitudes and Racial Relations». Journal of Applied Sociology [en línea], 8, 339-344. <http://www.brocku.ca/MeadProject/Park/Park_1924.html> [Consulta: 29 abril $2014]$.

- (1926). "The Concept of Position in Sociology». Papers and Proceedings of the American Sociological Society [en línea], 20, 1-14. <https://www.brocku.ca/MeadProject/Park/Park_1926a.html> [Consulta: 29 abril $2014]$.

- (1999). "La comunidad urbana como modelo espacial y orden social». En: PARK, Robert E. La ciudad y otros ensayos de ecología urbana. Barcelona: Ediciones del Serbal.

Penchaszadeh, Ana Paula (2009). «La cuestión del extranjero: Una mirada desde la teoría de Simmel». Revista Colombiana de Sociología, 31, 51-67.

Rammstedt, Otthein (1994). "L'étranger de Georg Simmel». Revue de Sciences Sociales de la France de L'Est [en línea], 146-153.

<http://www.revue-des-sciences-sociales.com/pdf/rss21-rammstedt.pdf> [Consulta: 29 abril 2014].

RAPHAEL, Freddy (1986). "L'étranger et le paria dans l'œuvre de Max Weber et de Georg Simmel / The Stranger and the pariah in the works of Max Weber and Georg Simmel». Archeves des Sciences Sociales des Religions [en línea], 61 (1), 63-81. <http://dx.doi.org/10.3406/assr.1986.2385>.

ReA, Andrea y Tripier, Marylise (2009). Sociología de la inmigración. Barcelona: Hacer.

REsÉnDIZ, Ramón (1998). «La sociología de Georg Simmel: Una mirada moderna de lo social entre la estética y la geometría». En Zabludovsky, Gina (coord.). Teoría sociológica y modernidad. México: UNAM / Plaza y Valdés, 155-185.

Ribeiro, Luci (2009). "La percepción de lo extraño: Contribuciones teóricas para la comprensión de los procesos de exclusión social: Simmel, Schütz, Elias y Bauman». Sociedad Hoy, 17, 115-127.

Richards, Evelleen (1994). «A Political Anatomy of Monsters, Hopeful and Otherwise: Teratogeny, Trascendentalism, and Evolutionary Theorizing», Isis, 85, 377-411.

Roiz, Miguel (1994). «La construcción de la diferencia cultural de los inmigrantes en los medios de información». Documentación Social, 97, 177-197.

SAbido, Olga (2009). «El extraño». En: León, Emma (ed.). Los rostros del Otro: Reconocimiento, invención y borramiento de la alteridad. Barcelona: Anthropos, 25-57.

SAID, Edward (2003). Orientalismo. Barcelona: Debolsillo. 
SAN Román, Teresa (1996). Los muros de la separación: Ensayo sobre alterofobia y filantropía. Bellaterra/Madrid: Servei de Publicacions de la Universitat Autònoma de Barcelona / Tecnos.

SAntamaría, Enrique (1994). “Extranjero”, nada menos que una palabra mayor». Papers, 43, 63-70.

- (2002a). La incógnita del extraño: Una aproximación a la significación sociológica de la «inmigración no comunitaria». Madrid: Anthropos.

- (2002b). «Inmigración y barbarie: La construcción social y política del inmigrante como amenaza». Papers, 66, 59-75.

SARTORI, Giovanni (2003). La sociedad multiétnica: Pluralismo, multiculturalismo y extranjeros. Madrid: Taurus.

SAYAD, Abdelmalek (2010). La doble ausencia. Barcelona: Anthropos.

Schütz, Alfred (2003). El problema de la realidad social: Escritos I. Buenos Aires: Amorrortu.

Serrano, Vicente (2010). Soñando monstruos: Terror y delirio en la modernidad. Madrid: Plaza y Valdés.

Shildrick, Margrit (1996). "Posthumanism and the Monstrous Body». Body \& Society [en línia], 2 (1), 1-15. <http://dx.doi.org/10.1177/1357034X96002001001>.

Simmel, Georg (1977). Sociología: Estudios sobre las formas de socialización. Tomo 2. Madrid: Revista de Occidente.

Solana, José Luis (2000). «Identidad cultural, racismo y antirracismo». En: Gómez, Pedro (coord.). Las ilusiones de la identidad. Madrid: Cátedra.

- (2009). «Sobre el racismo como ideología política: El discurso anti inmigración de la nueva derecha». Gazeta de Antropología [en línea], 25 (2), artículo 55. <http://www.ugr.es/-pwlac/G25_55JoseLuis_Solana_Ruiz.pdf> [Consulta: 20 diciembre 2012].

Terrén, Eduardo (2001). «La conciencia de la diferencia étnica: Identidad y distancia cultural en el discurso del profesorado». Papers, 63-64, 83-101.

Thériault, Barbara (2003). Le musulman et la métaphore de "l'étranger». Conferencia presentada en la mesa redonda sobre las comunidades árabes y musulmanas [en línea]. Montrèal, 18 de marzo.

<http://www.liguedesdroits.ca/assets/files/education_droits/SEM-2003-03-00-racisme-theriault.pdf> [Consulta: 29 abril 2014].

Todorov, Tzvetan (2008). El miedo a los bárbaros. Barcelona: Galaxia Gutenberg / Círculo de Lectores.

- (2010). Nosotros y los otros: Reflexión sobre la diversidad humana. Madrid: Siglo XXI.

Touraine, Alain (2008). La «dieta Touraine». <http://www.casamerica.es/contenidoweb/la-dieta-touraine> [Consulta: 29 abril 2014].

WAGNER, Bernd (2006). "El diálogo intercultural y su impacto para la pedagogía y el desarrollo sostenible en Alemania». Revista Interuniversitaria de Formación del Profesorado, 20 (1), 179-189.

Waldenfels, Bernhard (1998). «La pregunta por lo extraño». Logos: Anales del Seminario de Metafísica, 1, 85-98.

Wolff, Kurt H. (1950). The Sociology of Georg Simmel. Nueva York: Free Press, 402-403.

Zamora, José Antonio (2012). «Racismo, xenofobia, antisemitismo en el horizonte de los flujos migratorios: Enfoques teóricos y teoría crítica». Arbor [en línea], 188 (755), 591-604. <http://dx.doi.org/10.3989/arbor.2012.755n3010>. 